\title{
GENDER DISCERNMENT AND THE IMPLICATION ON NIGERIA POLICY
}

\author{
S. D. EDINYANG AND ANGIATING, LUCY ALOYE \\ (Received 10, August 2018; Revision Accepted 11, December 2018)
}

\begin{abstract}
Gender distinct treatment is all pervasive from the down of civilization. It has been continuing over centuries. It shows up in different forms and takes many other dimensions. It takes place in our families even in the society as a whole. Irrespective of economic condition and social standing, gender discrimination has been a cry of many, yet policies have been put in place where the right of girls and women should be protected. In the light of the above, the paper discussed the concept of gender, gender discernment, implication of gender discernment on the policy, rationale behind gender policy, governing standard of the national gender policy, the intent and goal of the national gender policy, above all, the crucial areas of gender gap. Findings were made in respect to the reason behind gender discernment. It could be said that various cultural and socio-economic factors, as well as lack of adequate health facilities for women are responsible for gender discernment. It was recommended that society should acknowledge equal democratic participation for accredited individuals and above all, government should make room for activities to reinforce women and girls like empowerment programmes.
\end{abstract}

\section{INTRODUCTION}

Regardless of the presence of constitutional provisions and responsibilities of regional and international human rights arrangement, the right of girls and women are grossly defiled and desecrated in our country and many other African countries.

Gender is the word used to represent social and personality variations between men and women; it is that which the society defines as masculine and feminine Webb2000. Attempts have been made in Nigeria to figure out the issue of women's right, responsibility and awareness in the early 80 's with a view to better the socioeconomic and political lots of Nigerian women as a whole. But the guiding principles and framework adopted then was feeble. This is due to the fact that gender matters have gone beyond the largely women empowerment approach and the narrow "Women in Development" concepts to a more and all enfolding approach of gender and developments CIDA 2006.

In recent times, an important discussion was held to redirect gender imbalance, enhance standard of living, and build a just society devoid of discrimination, harness full potentials of all social groups, regardless of sex or circumstance that can give both women and men recognized voices in decision making and policy implementation. The attainment of gender value is not only seen as end in itself and human right issue, but as a necessary level for the achievement of sustainable growth.

\section{S. D. Edinyang, Department of Social Science Education University of Calabar, Calabar Nigeria.}

A. L. Aloye, Department of Social Science Education University of Calabar, Calabar Nigeria. 
THE CONCEPT "GENDER"

Gender is the division of people into two

categories "men" and "women" .through interaction with caretakers, socialization in childhood, peer pressure in adolescence, and gendered work and family roles, women and men are socially constructed to be different in behaviour, attitudes and emotions. The gendered social order is based on and maintains these differences" (Borgatta\& Montgomery, 2000).

Gender is used to describe those characteristics of women and men, which are socially constructed, while sex refers to those which are biologically determined. People are born female or male but learn to be girls and boys who grow into women and men. This learned behaviour makes up gender policy identity and determines gender roles (WHO, 2002).

\section{GENDER DISCERNTMENT}

People model gender roles for us throughout our lives. Boys wear pants, girls wear skirts or dresses. Some toy stores have "boy" sections, with dump trucks and footballs and "girls" section with Barbie dolls and play kitchen. Boys who like rough-house may be described as "unladylike" through this process of socialization we develop our discernment of gender (Myers, 2007).

This continues into adulthood. Certain professions have historically been associated with women (e.g ("nurse", "teacher"). Others have historically been associated with men (e.g "mailman", "policeman", "fireman"). (Trombley, 2003).

Therefore discernment tends to view the world selectively, noticing what fits into the norms and expectations we have already internalized (Wenham \& Carson, 1994).

\section{IMPLICATIONS OF GENDER DISCERNMENT}

A wrong perception of the concept of gender by policy makers, charged with the responsibility for policy articulation and execution continues to challenge the attainment of gender equality and women's empowerment goals. There is still evidence that gender education has not permitted all levels of the populace,thus the impression that gender issues are exclusively about women still persists. Similarly, the impression that gender issues negatively challenge accepted norms and value of marriage, family and religion is rife. Many stakeholders believe that gender concerns should be addressed only within the Ministry of
Women Affairs and Social Development. Example of its implications,

i. Resource Management and Utilization: Gender imbalance substantially limits women's access to control over and use of service and productive resources. Women face numerous challenges within the agricultural sector, including lack of control over land, capital and even their own labor. Other challenges include lack of access to appropriate technologies, exploitation by marketers or service providers and lack of access to productive opportunities (FMWAASD, 2006).

ii. Productivity: Despite the contribution of women in agricultural sector, their role in promoting economic growth and social stability continues to be inadequately recognized and undervalued. The following factors are responsible:

- $\quad$ The male dominated culture in Nigeria which gives women an inferior position in society

- Customs that forbids women from owning land and the sexual division of labour which keeps women subordinate to men; and

- $\quad$ The problem of unpaid productive activities performed by women at the domestic front. (FMWAASD, 2006)

Given the above, appropriate gender sensitive policy that dismantles every form of discrimination against women in agricultural production and land use system will be a priority policy for implementation.

iii. Rights Delegation: A gender audit of Nigeria's local laws and policies affirms that, until very recently, many legal instruments were discriminatory and/or, at best, gender blind. Ranging from the constitution to the criminal code, local edicts to customary laws, women's right have been systemically undermined.

iv. Macro-economic Framework: another dimension of gender based marginalization can be perceived in unwritten norms and traditions which shape and influence organizational culture and practices. Failure to address the discriminatory aspects of frameworks and policies in all sectors will impede efforts to realize the MDGs, NEEDS/SEEDS and other international developments goals.

v. Energy: Declining supplies of electricity is a major problem throughout Nigeria. Inconsistent 
supplies and high costs, especially in rural areas for domestic use and small scale food processing also increase women's dependence on fuel wood. Energy availability and affordability has time and poverty implications for both women and men.

However, due to the preponderance of women for cottage production and informal domestic purposes, there exist a need for interventions to be guided towards reducing women's drudgery; and increasing productivity and thereby family incomes. (FMWAASD, 2006).

\section{WHAT IS THE RATIONALEBEHIND GENDER POLICY?}

Gender policy emerged due to the permissive nature of gender discrimination worldwide.Convenience to control over resources in both economic and political sphere is distending hence, promoting gender equality is crucial if not necessary, a contributing factor to development. In 1984, it was globally expressed at the United Nations Universal Declaration of Human Rights (UDHR), the guiding principles of the secular state and human right culture whereby almost all the countries of the world agreed to a basic common standard of human right while also prohibiting discrimination on ground of race, religion or sex. Even though the human right exists in national constitution, it continues to encounter many impediments in relations to culture and religious practices which overpowers patriarchal societies and pre-date the regime of global human rights imperatives.

Although, the human right exist in national constitutions, it continues to encounter many impediments in relations to culture and religious practices which overpower respected societies and precede the regime of global human rights imperatives.(NGP, (2007).

African countries remain prevalent towards violation of human rights in the area of marriage, inheritance and divorce, as a result of coexistence of statutory religious and traditional systems.Despite the existence of constitutional provisions and commitments to regional and international human rights treaties and conventions, the right of women and girls are grossly violated and devalued in Nigeria and many African countries. This is known in the overall low "Gender Development Index" in the country and manifested in low participation of women in paid employments, politics, leadership, decision making and equally high rate of physical and sexual harassment and assault, trafficking, marital rape, early/force marriage and different phases of harmful traditional practices against women and girls (Sani, 2013).

With the exclusion of equal opportunity commission in the country, and weak legislature structure to protect the right of women, development opportunities continue to elude women. To aggravate the situation, the available or existing policy document (e.g National Policy on Women) is not capable of challenging the structure, thus gender discrimination and general devaluation of women,conceive within the realities of the government macro-policy plans, including its resources allocation framework. The operation of ministry of women affairs and intergovernmental programmes of development patterns remain the only interaction medium of women focused between governments resources and activities. The projects were hardly institutionalized or assumed permanence. NGP, Federal Ministry of Women Affairs and Social Development (2007).

Based on the experience of the past years, conclusions has been made that a different approach is needed to fulfill women empowerment and that although the empowerment of women remains critical to the achievements of gender balance, gender balance or equality policy initiatives must focus on imbalance of power relations between men and women and institutional transformation, as a means of social justice empowerment and poverty reduction NGP, Federal Ministry of Women Affairs and Social Development, (2007).

\section{STANDARDS OF THE NATIONAL GENDER POLICY}

A policy is a contract of insurance that is geared towards achieving targeted goals. Hence, every policy should have a guiding principle and framework that will guide the smooth running of its plans so as to achieve the rationale behind the enactment. The National gender policy is not an exception. The general vision and mission for the implementation of its laudable plans emerged from the perceived priorities from the situation analysis.Field findings from stake holders during national and zonal consultations and in accordance with other global regional as well as national best practices. The achievement of a just and gender equitable society where men and women will contribute with maximum quota to development at all levels of governance are the main focus of the policy.(NGP, 2007). 
To entrench a clear vision and scheme to guide the process of developing laws, policies and practices that will ensure equal rights and opportunities for women and men in all areas and structures of government as well as in the work places, the community and family, is the main goal of the national gender policy. NGP, Federal Ministry of Women Affairs and Social Development (2007).

In view of the mandate given,specific goals of the national gender policy are :

1. To form an enabling environment for translating government commitment to gender balances in reality.

2. Create polices, programmes structures and mechanism to empower women, and to transform gender relations in all aspects of work at all levels of government as well as within the broader society

3. Ensure that gender considerations are effectively integrated into all aspects of government policies, activities and programmes.

4. To form an institutional framework for the advancement of the status of women as well as the achievement of gender equality.

5. Advocate for the promotion of new attitudes, values and behavior and a culture of respect for all human beings in line with the new policy.

6. To reinforce the voices of women in civil societies in parliaments and other legislatures who have already made visible impact by challenging gender blind laws and policies.

7. Enhancing the work that is already being undertaken by the ministries at the national, state and local government levels and those of other development agencies committed to issues of women empowerment, gender balance and fairness for all.

8. Guide the development of the National Gender Action Plan - NGAP (NGP, 2007)

\section{THE INTENT AND GOAL OF THE NATIONAL GENDER POLICY}

Nigeria adopted the gender policy in order to focus the gender context in all aspects of planning policy, developing legislation and transportation activities. The aim of the gender policy is to focus on approaching the catalogued inequalities between women and men in the society without ignoring the fundamental difference between them.

Approbation of women, being the major priority as a way of accomplishing gender equality is based on the assertion that gender inequality is about power relations between men and women. And as such, the flawless advantages of both parties should be put into cognizance in any policy, plan or practices that seek gender uniformity in order to balance these power relations.

The national women machinery is not the only organ left with the obligations of actualizing the policy, stakeholders are also to share the responsibility. The gender policy will articulate the problems, challenges and directives, aims, pledges and outputs, outlined to achieve gender equality as well as a framework for implementation and monitoring (NGP, 2007).

The gender policy is a comprehensive document for total national remodeling and transformation towards poverty reduction, tenable and equitable growth, the more reason why it is concatenated within the framework of the National Economic Empowerment Development Strategy (NEEDS), Gender equality will therefore address other essential goals within the context of (SEEDS)State Economic Empowerment and Development strategy, (LEED) Local Economic Empowerment and Development strategy and their likely response.(NGP, 2007).

Among other things, the gender policy will also work towards the advancement of a common set of ideas in all cultural socio-economic opinion of gender context, situated on a common opinion of gender concepts as the policy. It will therefore figure out clear vision of what the nation aims to achieve through gender equality, deriving from our common vision as a country as well as within the evaluation of gender debates in the international area.

Innovation is the ambition of gender equality and like all processes of transformation, it may encounter encumbrances in the form of interest of individuals, groups and organizations. However, the Nation gender policy for Nigeria is stationed on widespread consultation at all levels of National development and is encased to undergo continuous fine tuning based on an active communication plan of action, continued sensitization and gender education as well as constant accouterment of facts and figures on gender status to promote evidence based gender agenda.

\section{CRUCIAL AREAS OF GENDER GAP}

The findings of the United Nation Development Fund for Women UNDFW (2007) revealed five important areas regarding the global patterns particularly between men and women. 
Namely;

1

2.

Economic Participation

Economic Opportunity

Political Empowerment

$\begin{array}{ll}\text { 4. } & \text { Educational Procurement } \\ 5 . & \text { Health and well being }\end{array}$

i. Economic Participation: The synergy of women in the workforce both quantitative and qualitative is now accepted not only as important for covering the level inequalities of poverty among women, but also very essential towards raising household income and the overall economic development of the nation. To this end, the notion of securing women as a mere recipient of help is not acceptable but rather, it is seen as a view strongly supported by facts that education, employment and ownership rights of women has a great influence on their strength to control their environment and contribute to economic progress of the nation.Two-third of world's poorest people, as such, globalization has further increased the existing insecurities and unbalanced for many poor women in the world as a result of the poor generated chances for the local manufacturers and entrepreneurs to reach foreign market, (NGP 2006:16)

ii. Economic opportunityEstimates of unemployment rate deviates extensively according to geopolitical zones.Between rural and urban centres, as well as between women and men. In 2003, women accounted for about $41 \%$ of the nation labour pool (14-70 years) and $45 \%$ of the unemployment white men bookmarked for $50 \%$ of the workforce and $55 \%$ of the unemployed.(Baba, 2013).

From 2001-2004, women constituted 29\%-31\% of the federal civil service cadre while men made up $69 \%-71 \%$. There is only an increase in $1 \%$ in the proportion of women in the federal civil service workforce from 2001-2004. Women are undoubtedly distorted both in entire national workforce and in the federal civil service in view of the fact that women integrate relatively $49 \%$ of the Nigeria population. (NGSB,2006).

iii. Political Empowerment: Political empowerment is the act of conferring legality or sanction of formal warrant. Political empowerment can be defined as the impartial representation of women in decision making formats (established or casual) and incorporation of women opinions in the inception of policies affecting their societies.(Scott, 2003). The interparliamentary union reports a world average of merely $15.6 \%$ participation by women in combined houses of parliaments. The demography of region offer few surprises, ranging from less than $6.8 \%$ in the Arab States and African countries, to $18.6 \%$ in the Americans and $39.7 \%$ in the Nordic states. The male still dominate the affairs of the three tiers of government when it comes to politics (The Local, State and Federal). There is only a very dainty amelioration in the number of women elected into political positions in 2003 when compared with 1999 figures. In 1999 women made up only $1.2 \%-3.6 \%$ of the elected members of senate, House of Representatives and State House of Assemblies and in 2003, the number increased from 3.75 to $5.8 \%$. More women have also been elected into positions both at state and federal government levels. In 1999, there were 12 female state assembly members out of 990 members, 13 female House of Representatives members out of a total 360, 3 female senators out of 109 members.(National Bureau of Statistics, 2004).

Nonetheless, in 2003, there were 39 female state assembly members, 21 female members of House of Representatives and 4 female senators (compared to the figures of 1999). Regardless of the advancement, these figures are a small or little representation of women, to whom constitutes half of the population in Nigeria. (NGSB, 2006).

iv. Educational Procurement: According to Ojo (2002), the enrollment of girls from 1970 to 1994 in primary education steadily increased from $30 \%$ to as high as $80 \%$. However, differences exist between enrolment of males and females in all levels of education. In addition, the dropout rate of girls was higher than boys and participation in Science, Technology, Engineering and Mathematics (STEM) classes were lower for girls than boys. In 2002, the combined gross enrollment for primary, secondary and tertiary schools for females was $57 \%$ compared to $71 \%$ for males (Ojo, 2002). This translates into fewer women in certain economic fields as well. The percentages of female workers in some selected professions were as follows:

Architecture:

$2.4 \%$

Quantity Surveyor:

$3.5 \%$

Lawyers/Jurist:

$25.4 \%$ 
vLecturers:

$11.8 \%$

Obstetrician and gynecologists: $8.4 \%$

Pediatricians:

$33.3 \%$

Media Practitioners:

$18.3 \%$

According to Ojo (2002) issues of gender equality in education have been subjects of much debate during the past decades and in all countries. In Nigeria, there are large disparities between the education that boys and girls receive. Many girls do not have access to adequate education past a certain age. Currently, the female adult literacy rate (ages 15 and above) for the country is $59.4 \%$ in comparison to the male adult literacy rate of $74.4 \%$. It is differences in education that have led to this gap in literacy. (According to the Central Bank of Nigeria, 2000) the gender gap in literacy rates at the rural level between boys and girls was $18.3 \%$ in favour of the boys overall.

However, in the age of 6-9 years (primary school ages), it was only $3.9 \%$ in favour of boys. This indicates that there is gender imbalances to educational attainment and development in Nigeria. According to the Examination Council of Nigeria (1994), there are still other problems, such as high rate of drop-out of female students, poor performance, reluctance on the part of female students to enroll in science based courses and poor classroom participation.

Across various geo-political delineations in Nigeria, a greater percentage of school-age girls are needlessly out of school, compared with the ratio applicable to boys of same age grouping. (Ogunjuyigbe, 2006).

According to Adeniran,(2007), gender disparity is also visible in the education of children with disabilities, a study revealed that only $37 \%$ of disabled females are literates compared to $57 \%$ for males. A reason for this situation is the cultural notion that the male will carry the family name while the female will marry. Also the option street begging by young disabled girls in order to earn income can inhibit their attendance of classes.

v. Health: One of the concepts that extensively variegate between women and men is health and wellbeing, which concerns their access to sufficient nutrition, healthcare and reproductive facilities as well as affairs of essential safety and rectitude of person. (NGSB, 2007).
The health of women is determined by a complex combination of various health determinants including income, social status, education, literacy, employment, working condition, social and physical environments, health, child development and genetic endowments. The millennium Development Goal (MDGs) call for $75 \%$ reduction of maternal mortality ratio and $66.66 \%$ reduction of child mortality (children under 5 years by 2015). The challenges to the achievement of these objectives in Nigeria include teenage pregnancy, harmful cultural factors, poverty, illiteracy, lack of health personnel and infrastructures particularly in rural areas etc. (NGSB 06:P4).

It has been discovered that so many factors or issues are responsible for gender discernment but few findings will be mentioned here as follows:

i. Cultural and socio-economic factor
ii. Lack of adequate health facilities for the
women
iii. Low income level of women
iv. Poor participation or representation in
politics.

\section{RECOMMENDATIONS}

Based on the findings of the study, it was recommended that:

i. Society should acknowledge equal democratic participation for accredited individuals ii. Government should create more rooms for activities to reinforce the women

iii. There should be empowerment programmes for women and girls

iv. Policies should be on ground to guide the women and there should be proper monitoring of the policies.

\section{CONCLUSION}

The main point of the National Gender Policy (NGP) is to promote gender sensitive and gender responsive culture in policy planning and national development. A major tool for the required social transformation shall be the promotion of gender mainstreaming in all public and private policies and programming priorities and in all organizational and community cultures in Nigeria. Gender equality principles shall therefore become a cultural norm, while women empowerment shall become a corporate responsibility. 


\section{REFERENCES}

Adeniran, A.I., 2007' Educational Inequalities and "Women's Disempowerment in Nigeria" Department of Sociology University of Lagos, Nigeria

Borgatta, E.F. and Montgomery R.J.V. 2000 Encylopedia of Sociology ( $2^{\text {nd }} \mathrm{ed}$. Vol 2$)$. New York: Macmillan Reference, USA.

Community care perspectives published in United Kingdom by J.W. Arrowsmith Ltd., Bristol.

CBN 2000. Annual Report and statement of Accounts 31December 2000. Canadian International Development Agency CIDA 2006.

Examination Council of Kenya 1994 Government Printers

Gender Situation Assessment and Analysis (GSAA) 2006. https://en.m.Wikipedia, Org>wiki Female Education in Nigeria

Myers, D.G., 2007 Psychology: Eight edition in modules. Holland, MI: Worth Publishers. NCAA, www.accoalition.org

National Bureau of Statistics 2004.

National Gender Policy, Federal Ministry of women Affairs and Social Development, 2007.

National Gender Policy, Situation Analysis and Framework. Federal Ministry of Women Affairs 2007.
Nigerian Gender Statistics Book, Federal Ministry of Women Affairs 2006.

Ogunjuyigbe, P.O., Ojofeitimi, E.O and Akinto, A. JsciEduTechnol 2006 15;2777. Science Education in Nigeria: An Examination of People's

Perceptions about female participation in $S$ cience, Mathematics and Technology. Doi;10.1007/s 10956-006-9014-6.

Ojo, A., 2002." Socio-Economic Situation” in Africa Atlases Nigeria, Paris-France, Les Editions J.A., PP 126-127.

Sani, M.K and Baba, U.Y., 2013. An analysis of Gender Inequality and National Gender Policy in Nigeria. International Journal of Scientific and Engineering. Vol. 4. ISSN 2229-5518.

Scott, L.E., 2003: Classical and Contemporary Sociological Theory, Text and Readings. Pine Forge Press, Los Angelis. Sage Pub Company.

Trombley, C., 2003. Who said women cant teach? God's vision for women in ministry. Gainesville, FL: Bridge-Lagos.

Webb R. and Tossel D., 2000: Social issues for careers. A World bank report,2010

World Health Organisation. 2002. Integrating gender perspectives into work of WHO. Switzerland: Author.

Wenham, G. and Carson, D., 1994. New bible commentary: $21^{\text {st }}$ century edition. Downer's Groveil: Inter-varsity press 